\title{
Treatment of a benign colorectal anastomotic stricture with a biodegradable stent
}
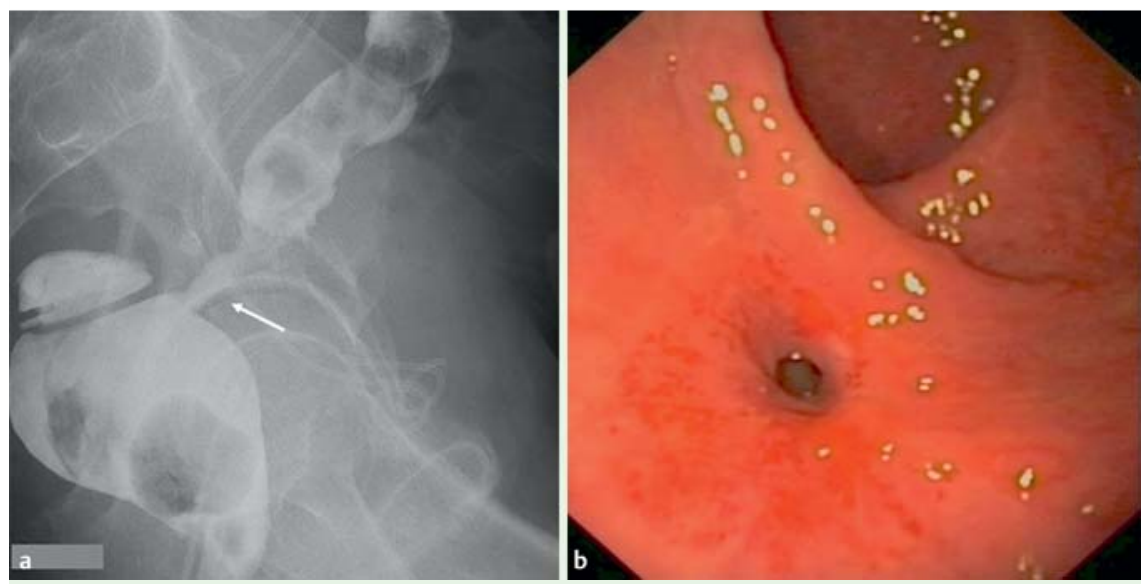

Fig. 1 The colorectal stricture visualized by use of: a contrast colonography (the arrow indicates the stricture at the colorectal anastomosis) and $\mathbf{b}$ endoscopy. The 2-cm long advanced stricture had a lumen less than $5 \mathrm{~mm}$ in diameter.
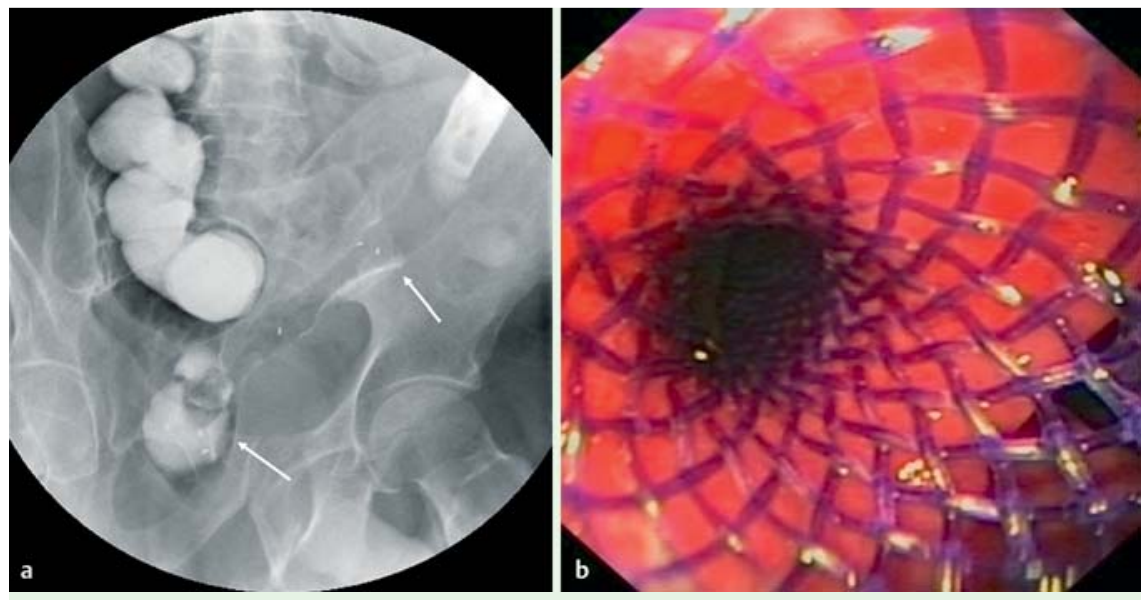

Fig. 2 Appearance of the biodegradable stent immediately after insertion, visualized by use of: a plain abdominal radiograph (arrows indicate the stent in place) and $\mathbf{b}$ endoscopy.

It is routine practice to use metal stents in the treatment of malign obstructions in the lower gastrointestinal tract [1]. However, metal stents are not suitable for benign conditions. Recently, treatment with biodegradable stents has been implemented for non-malignant diseases in the upper gastrointestinal tract [2,3], but there is no case in the literature reporting on the use of biodegradable stents for benign conditions in the lower gastrointestinal tract. Here we describe a case with a benign stricture in a colorectal anastomosis, treated with a biodegradable stent.

A 68-year-old man underwent sigmoid stoma reversal after Hartmann's procedure (for perforated diverticulitis). The pa- tient developed a symptomatic stricture in the colorectal anastomosis ( $\bullet$ Fig. $\mathbf{1}$ ), and biopsies were benign. Despite three endoscopic dilations, the patient suffered from repeated symptomatic stricture recurrence.

Due to significant co-morbidity, the patient was not suitable for surgical treatment. As an alternative approach, a self-expanding biodegradable esophageal stent (SX-Ella stent; ELLA-CS, Hradec Kralove, Czech Republic) was chosen. The lumen of the stricture was less than $5 \mathrm{~mm}$ and was dilated up to $12 \mathrm{~mm}$. The biodegradable stent was deployed in the middle of the stricture using a guide wire (৫ Fig. 2). The position of the stent was

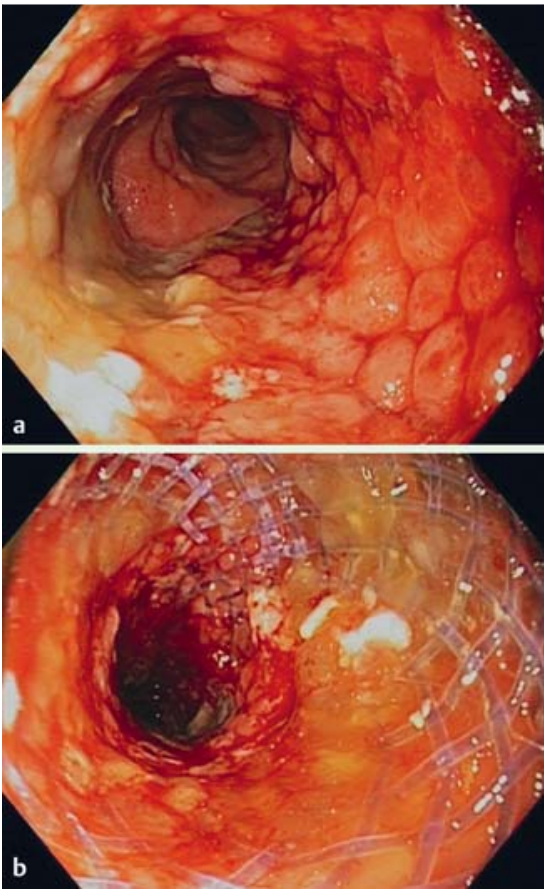

Fig. 3 Endoscopic images 6 weeks after stenting showing partial biodegradation of the stent in the: a proximal and $\mathbf{b}$ distal part of the colorectal stricture.
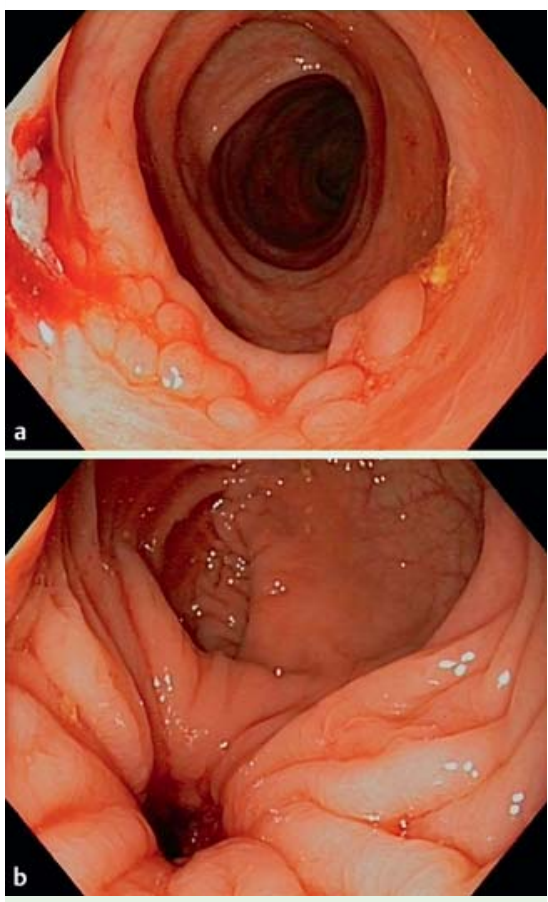

Fig. 4 Endoscopic images 5 months after stenting, showing complete disappearance of the stent with a patent lumen in the: a proximal and $\mathbf{b}$ distal part of the colorectal stricture, as well as a hyperplastic tissue reaction. 
monitored 4 days later and the lumen further dilated to $15 \mathrm{~mm}$. The stent position was monitored 6 weeks after deployment; the stent was shown to be partially reabsorbed ( Fig. 3). The patient was still asymptomatic and a colonoscopy revealed complete biodegradation of the stent 5 months later ( $\bullet$ Fig. 4a). At this time, the lumen had reduced to $8 \mathrm{~mm}$ ( $\bullet$ Fig. 4 b) and was therefore dilated up to $18 \mathrm{~mm}$. A follow-up was performed 2 years later, which revealed that the patient had no clinical symptoms although the size of the lumen had reduced.

This unique case demonstrates that treatment with biodegradable stents is also feasible in patients with benign strictures in the lower gastrointestinal tract.

Endoscopy_UCTN_Code_TTT_1AQ_2AF

Competing interests: None
E. Toth ${ }^{1}$, J. Nielsen ${ }^{1}$, A. Nemeth ${ }^{1}$,

G. Wurm Johansson ${ }^{1}$, I. Syk ${ }^{2}$, P. Mangell ${ }^{2}$, P. Almqvist ${ }^{2}$, H. Thorlacius ${ }^{2}$

1 Endoscopy Unit, Department of Clinical Sciences, Malmö, Skåne University Hospital, Lund University, Malmö, Sweden

2 Surgery Unit, Department of Clinical Sciences, Malmö, Skåne University Hospital, Lund University, Malmö, Sweden

\section{References}

1 Lee JH, Ross WA, Davila R et al. Self-expandable metal stents (SEMS) can serve as a bridge to surgery or as a definitive therapy in patients with an advanced stage of cancer: clinical experience of a tertiary center. Dig Dis Sci 2010; 55: 3530-3536

2 Vandenplas Y, Hauser B, Devreker T et al. A degradable esophageal stent in the treatment of a corrosive esophageal stenosis in a child. Endoscopy 2009; 42: E132-E133

3 Repici A, Vleggaar FP, Hassan C et al. Efficacy and safety of biodegradable stents for refractory benign esophageal strictures: the BEST (Biodegradable Esophageal Stent) study. Gastrointest Endosc 2010; 72: 927-934
Bibliography

DOI 10.1055/s-0030-1256462

Endoscopy 2011; 43: E252 -E253

(c) Georg Thieme Verlag KG Stuttgart · New York . ISSN 0013-726X

Corresponding author

E. Toth, MD, PhD

Endoscopy Unit

Department of Clinical Sciences

Skåne University Hospital

Lund University

20502 Malmö

Sweden

Fax: +46-40-338699

ervin.toth@med.lu.se 